\title{
Impact of Stratified Interventions in University Reopenings
}

Authorship: Yiwei Zhang, MS ${ }^{1}$, Zhuoting Yu, BS ${ }^{2}$ Akane Fujimoto, MS², Pinar Keskinocak, PhD ${ }^{2}$, Julie L. Swann, PhD ${ }^{1}$

1. Department of Industrial and Systems Engineering, North Carolina State University, Raleigh, NC, United States of America

2. Department of Industrial and Systems Engineering, Georgia Institute of Technology, Atlanta, GA, United States of America

* Corresponding Author: Julie Swann, jlswann@ncsu.edu; Office phone (919-515-6423); NC State University; 915 Partners Way; Campus Box 7906, Raleigh, NC 27695

\begin{abstract}
:
More than 4,000 colleges and universities in the U.S. are scheduled to start a new semester in August or September, 2021. Many colleges require Covid-19 vaccination, as well as some combination of face coverings or diagnostic testing, while others do not (in some cases due to governance structure). Large state universities may especially have limitations and are not requiring vaccination, testing, or indoor face coverings, nor offering hybrid classes (to promote physical distancing). Group living quarters or classrooms with densely packed students are among the riskiest settings for infectious disease spread.
\end{abstract}

\section{Introduction:}

We project cases that may result from the Delta variant of SARS-CoV-2 that is currently circulating widely in the U.S., under various scenarios of initial protection and interventions. Earlier studies of college testing $(1,2)$ did not consider existing immunity or infections entering the community from external sources, or interventions that may help reduce the transmission (e.g., masks), and previous analysis of K-12 schools (3) did not include different test types or large sizes.

\section{Methods}

We built a Susceptible-Infected-Recovered (SIR) model (4) where vaccinated or previously infected individuals have partial immunity, i.e., move to the Recovered state. The population of 5,000 is well-mixed with 10 additional infections arising weekly from external sources (20 for sensitivity analysis). While some colleges are much larger (e.g., over 30,000 students), it is unlikely that the entire campus simultaneously mixes, so the 5,000 well-mixed population provides a good approximation; the model produces similar results if the initial infections and weekly external infections are scaled proportionally to community size. The model is run for one semester (107 days), and the incoming rate of infections (i.e., the percentage of the population infected at the beginning) is $0.5 \%$ (low) or $2.0 \%$ (high); if gateway testing is in place then there are no incoming infections. The reproductive rate $R_{0}$ is either 4.0 (baseline) or 5.0 (high), following the genomic surveillance and estimates of increased infectivity of the Alpha and Delta variants of SARS-CoV-2. $40 \%$ of the infections are asymptomatic (5), and the average duration of infectivity is 10 days (6). Screening tests have sensitivity and specificity of either $(0.7,0.9)$ for rapid or $(0.85,0.95)$ for high-accuracy. A positive test leads to self-isolation, whose length is equivalent to infectivity length. A proportion $(33 \%, 50 \%$ or $75 \%)$ of all non-isolated individuals are tested weekly regardless of vaccination status. Mask wearing is assumed to reduce infectivity by $50 \%$ (universal mask wearing) or $25 \%$ (partial mask wearing) (7), where masks are used across all campus settings, including social events. Hybrid classrooms or other distancing reduces $\mathrm{R}_{0}$ additionally by 0.5 .

\section{Results}


Without masks or surveillance testing in place, in a university with incoming protection of $50 \%$, initial prevalence of $0.5 \%$, the delta variant may infect more than $75 \%$ of the susceptible population during the semester. If masks are regularly worn in $25 \%$ (50\%) of college settings, infections could be reduced to $59 \%$ or $24 \%$ of the beginning susceptible population. (See Figure I). Infections rise substantially after about one month. The test positivity on day 30 , occurring from screening a portion of the entire population, is indicated on the figure.

Screening can be used to get the outbreak more under control. With incoming protection of $50 \%$ (75\%), weekly testing of $50 \%$ of the population with a high-accuracy test results in infections of $57 \%$ (21\%) of the susceptible population without masks or $13 \%(9 \%)$ of the susceptible population if masks are worn at $50 \%$ level.

If Delta is more infectious $\left(R_{0}=5.0\right), 75 \%$ of the susceptible population become infected within the semester, even with weekly testing of $75 \%$ of the population with a rapid test (or $50 \%$ of the population with a high-accuracy test). Only with the addition of masking can the infections be reduced further, down to $19 \%$ (See Figure 2).

If the incoming rate of infections is high (2\%), $8 \%$ more people get infected compared to the baseline scenario with $\mathrm{R}_{0}=4.0,25 \%$ masks, and $50 \%$ PCR testing.

Number of infections is reduced with a higher level of mask usage (e.g., approximately $13 \%$ points reduction in infections when mask usage goes up from $25 \%$ to $50 \%$ in similar scenarios), increased testing (e.g., about $3 \%$ fewer infections when the Percentage of population tested weekly goes up from $50 \%$ to $75 \%$ in similar scenarios), increased testing accuracy (e.g., about $2 \%$ fewer infections under high-accuracy versus rapid testing in similar scenarios). Gateway testing also offers benefits ( $11 \%$ fewer infections when gateway testing is in place versus not, in comparable scenarios).

The single best intervention for reducing infections is to have a higher incoming protection level. On average, incoming protection of $75 \%$ vs. $50 \%$ drops the infections from $48.2 \%$ to $27.5 \%$ of the susceptible population.

\section{Discussion}

Colleges and universities across the U.S. are facing challenges in keeping Covid-19 cases low in their campus communities. Large public universities have particular challenges as their ability to require masks, vaccination, and regular testing may be limited due to local governance or resource limitations. While encouraging vaccinations can have a significant impact on enabling in-person learning, only $34 \%$ of $18-24$ year olds were vaccinated by the end of June, 2021 (8).

Several universities do not have accurate knowledge of the vaccination rates or incoming protection (which depends on vaccination, previous disease, and timing) of their community, as their estimates are often based on surveys (9). Universities can compare weekly test positivity to projected values under several scenarios to better understand the current state of a given community, and put interventions in place accordingly to meet desired goals.

Given existing protection levels, mask wearing, and regular testing can reduce infections on campus (and likely surrounding communities). Hybrid classrooms can also reduce infections, though may not be as desirable for the college experience. Masks are likely to be the cheapest intervention though may not be worn in all college settings. Even if a college cannot require it alone, statewide mandates may apply.

Slowing infections on campus will allow additional people to be vaccinated, which largely prevents severe diseases and death. Moreover, slowing spread is imperative in states where hospitals are at risk of being overburdened, which further increases mortality in the community. Employing interventions such as masks, testing, or distancing can help college campuses stay in-person safely, ultimately promoting learning, positive college experiences, and good outcomes in the community. 
medRxiv preprint doi: https://doi.org/10.1101/2021.08.30.21262805; this version posted September 5, 2021. The copyright holder for this preprint (which was not certified by peer review) is the author/funder, who has granted medRxiv a license to display the preprint in perpetuity.

\section{It is made available under a CC-BY 4.0 International license .}

\section{FIGURES AND TABLES}
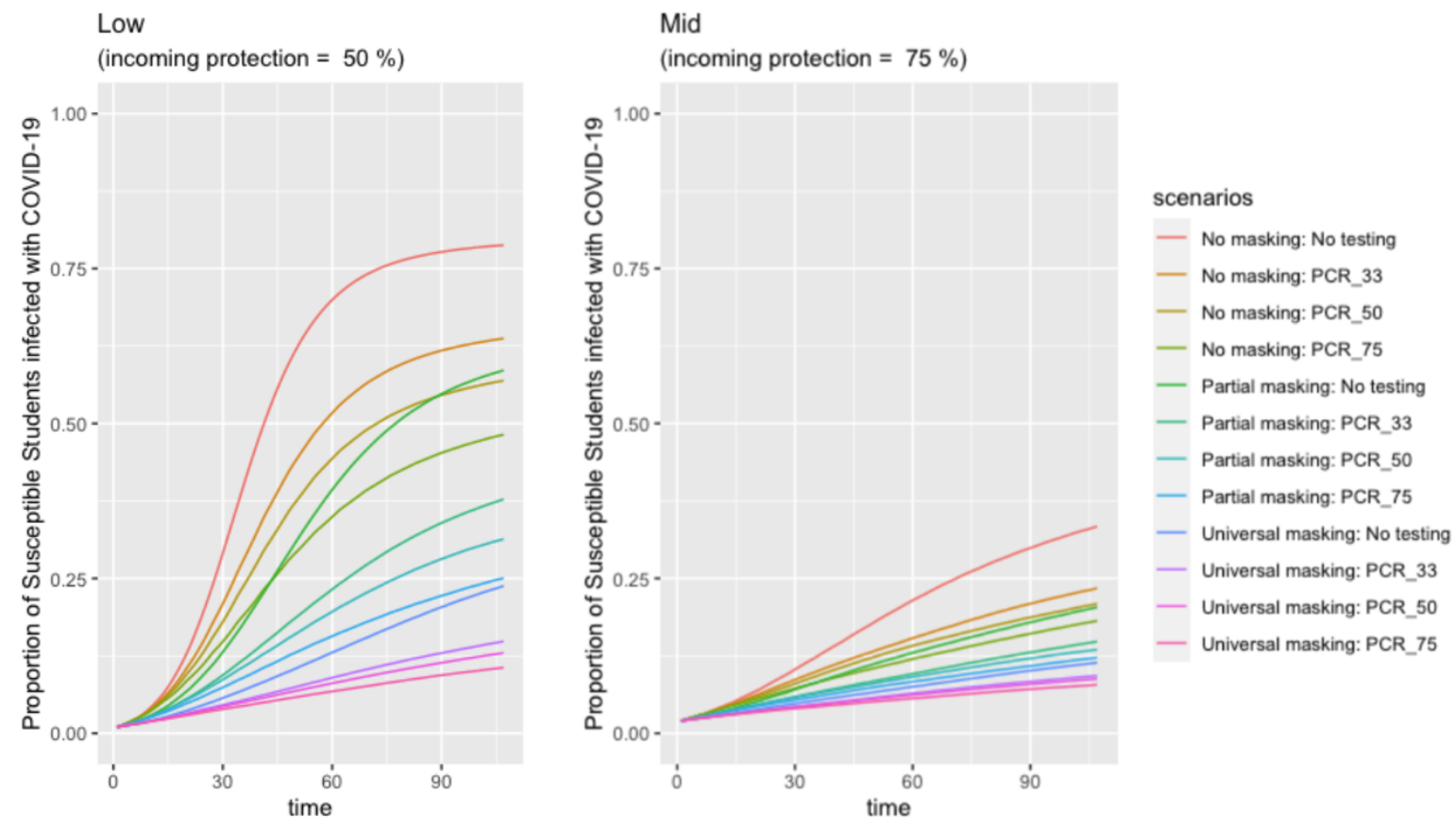

Figure 1: Projected Spread of COVID-19 under different PCR Testing rate and masking strategies. Both of the panels above represent how the proportion of susceptible students infected with COVID-19 increases under certain incoming protection levels ("Low": 50\%; "Mid": 75\%) throughout the semester (107 days). "No masking", "Partial masking" and "universal masking" scenarios reflect the disease reproduction number of 4, 3 and 2, respectively. Additionally, PCR testing rates of $0 \%, 33 \%, 50 \%$ and $75 \%$ are also included within each setting and masking scenarios. 
medRxiv preprint doi: https://doi.org/10.1101/2021.08.30.21262805; this version posted September 5, 2021. The copyright holder for this preprint (which was not certified by peer review) is the author/funder, who has granted medRxiv a license to display the preprint in perpetuity.

\section{It is made available under a CC-BY 4.0 International license .}
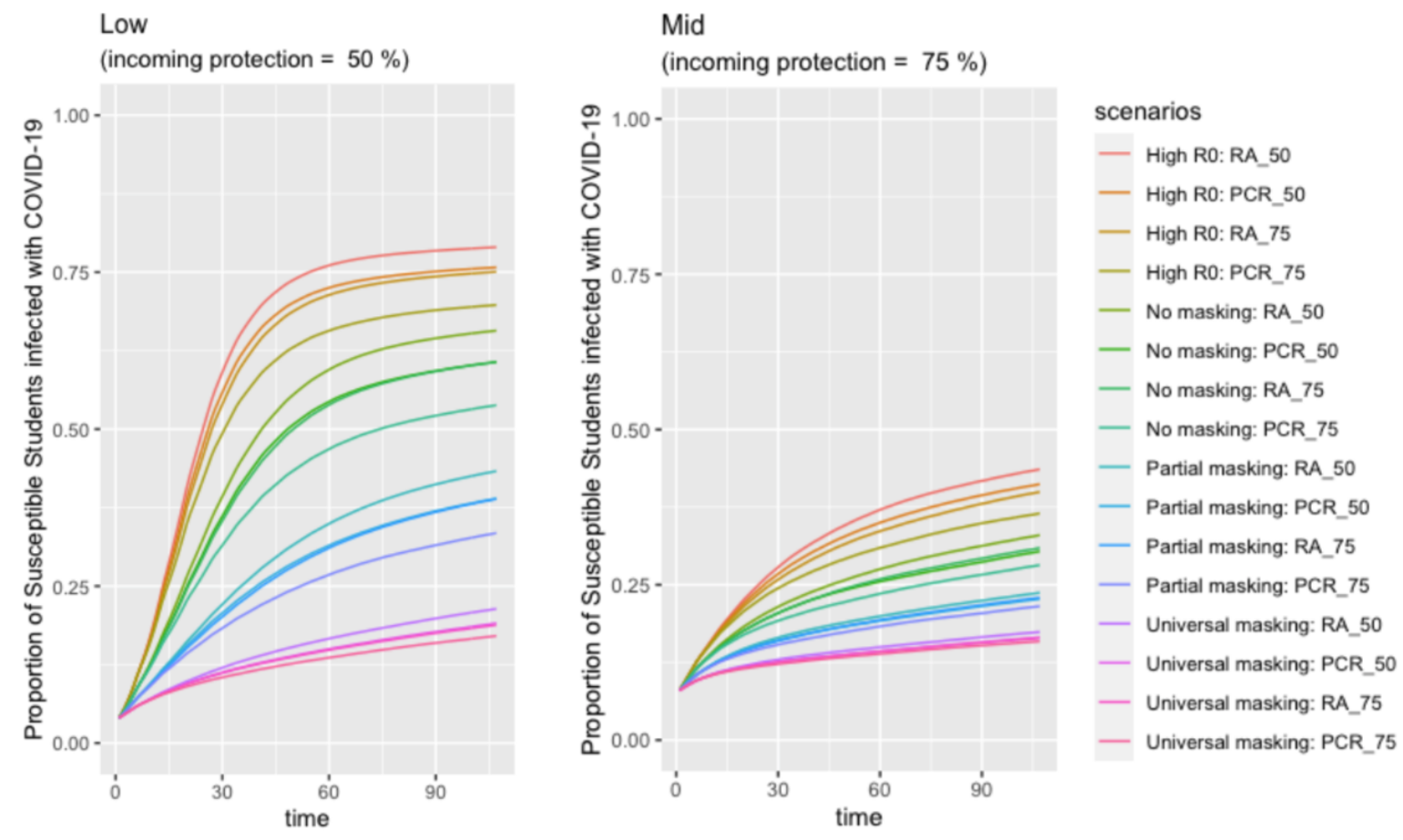

Figure 2: Projection of COVID-19 spread under school testing and masking policies. The panels above represent the proportion of susceptible students infected with COVID-19 with epidemiological settings of two different incoming protection levels. "Low" and "Mid" represent 50\% and 75\%, respectively. "High R0" reflects the disease reproductive rate of 5. "No masking", "Partial masking" and "universal masking" scenarios reflect the disease reproduction number of 4, 3 and 2, respectively. Besides, PCR testing and Rapid testing rates of $50 \%$ and $75 \%$ are also included within each setting and masking scenarios. 


\begin{tabular}{|c|c|c|}
\hline Parameters & Description & Value \\
\hline $\mathrm{T}$ & Number of days considered & 107 \\
\hline ppl_size & School size & 5000 \\
\hline prob0 & Proportion of infections that are symptomatic & 0.6 \\
\hline prevalence & Initial infections within the population & $0,0.005,0.02$ \\
\hline i_new & New infections per week & 10 \\
\hline recovered & Incoming protection & $0.5,0.75$ \\
\hline test_level_pcr & Testing level of PCR test & $0,0.33,0.5,0.75$ \\
\hline test_level_rap & Testing level of Rapid test & $0,0.5,0.75$ \\
\hline$\beta \_a, \beta \_s$ & $\begin{array}{l}\text { Transmission rate of due to contact between susceptible and } \\
\text { asymptomatic/symptomatic infected subjects }\end{array}$ & $\begin{array}{c}(0.3125,0.625) \\
(0.25,0.5) \\
(0.1875,0.375) \\
(0.125,0.25)\end{array}$ \\
\hline Y_a , Y_s & $\begin{array}{l}\text { Rate of recovery of an asymptomatic/symptomatic infected } \\
\text { individual }\end{array}$ & $0.1,0.1$ \\
\hline$\mu$ & Mortality rate & 0 \\
\hline $\mathrm{Ca}, \mathrm{Cs}$ & $\begin{array}{l}\text { Isolation compliance rate for asymptomatic/symptomatic } \\
\text { infected and tested individuals }\end{array}$ & $0.7,0.9$ \\
\hline FNpcr,a , FNpcr,s & $\begin{array}{l}\text { False negative rate of PCR test when individual is } \\
\text { asymptomatic/symptomatic }\end{array}$ & $\begin{array}{l}(15 \%, 15 \%) \\
(7.5 \%, 7.5 \%)\end{array}$ \\
\hline FNrap,a , FNrap,s & $\begin{array}{l}\text { False negative rate of rapid test when individual is } \\
\text { asymptomatic/symptomatic }\end{array}$ & $\begin{array}{l}(30 \%, 30 \%) \\
(15 \%, 15 \%)\end{array}$ \\
\hline FPpcr,a , FPpcr,s & $\begin{array}{l}\text { False positive rate of PCR test when individual is } \\
\text { asymptomatic/symptomatic }\end{array}$ & $\begin{array}{c}(5 \%, 5 \%) \\
(2.5 \%, 2.5 \%)\end{array}$ \\
\hline FPrap,a , FPrap,s & $\begin{array}{l}\text { False positive rate of PCR test when individual is } \\
\text { asymptomatic/symptomatic }\end{array}$ & $\begin{array}{c}(10 \%, 10 \%) \\
(5 \%, 5 \%)\end{array}$ \\
\hline
\end{tabular}


medRxiv preprint doi: https://doi.org/10.1101/2021.08.30.21262805; this version posted September 5, 2021. The copyright holder for this preprint (which was not certified by peer review) is the author/funder, who has granted medRxiv a license to display the preprint in perpetuity.

It is made available under a CC-BY 4.0 International license.

\section{References}

1. Paltiel, A. D., Zheng, A., \& Walensky, R. P. (2020). Assessment of SARS-CoV-2 Screening Strategies to Permit the Safe Reopening of College Campuses in the United States. JAMA Network Open, 3(7), e2016818-e2016818. doi:10.1001/jamanetworkopen.2020.16818

2. Chang, J. T., Crawford, F. W., \& Kaplan, E. H. (2021). Repeat SARS-CoV-2 testing models for residential college populations. Health Care Management Science, 24(2), 305-318. doi:10.1007/s10729-020-09526-0

3. Zhang, Y., Johnson, K., Hassmiller Lich, K., Ivy, J., Keskinocak, P., Mayorga, M., \& Swann, J. L. (2021). COVID-19 Projections for K12 Schools in Fall 2021: Significant Transmission without Interventions. MedRxiv 2021.08.10.21261726; doi: https://doi.org/10.1101/2021.08.10.21261726

4. Yu, Z., Fujimoto, A. B., Keskinocak, P., \& Swann, J. L. (2021). The Impact of COVID-19 Testing on College Campuses. medRxiv, 2021.2008.2016.21262153. doi:10.1101/2021.08.16.21262153

5. Oran, D. P., AM, \& Topol, E. J., MD. (2020, September 1). ACP Journals. Prevalence of Asymptomatic SARS-CoV-2 Infection. https://doi.org/10.7326/M20-3012

6. Johansson, M. A., PhD, Quandelacy, T. M., PhD, MPH, \& Kada, S., PhD. (2021, January 7). SARS-CoV-2 Transmission From People Without COVID-19 Symptoms. Global Health | JAMA Network Open | JAMA Network. https://jamanetwork.com/journals/jamanetworkopen/fullarticle/2774707

7. Mitze, T., Kosfeld, R., Rode, J., \& Wälde, K. (2020). Face masks considerably reduce COVID-19 cases in Germany. Proceedings of the National Academy of Sciences, 117(51), 32293-32301. doi:10.1073/pnas.2015954117

8. Baack, B. N., Abad, N., Yankey, D., et al. COVID-19 Vaccination Coverage and Intent Among Adults Aged 18-39 Years - United States, March-May 2021. MMWR Morb Mortal Wkly Rep, 2021;70: 928-933. doi: http://dx.doi.org/10.15585/mmwr.mm7025e2external icon.

9. Romero, R. (2021). Fake COVID-19 vaccination cards worry college officials. AP News. Available at: https://apnews.com/article/coronavirus-education-fake-vaccination-cards-8c4ca2b4d54434c2fc022b34087df8cb. Accessed on Aug. 18, 2021.

10. Brooks-Pollock, E., Christensen, H., Trickey, A. et al. High COVID-19 transmission potential associated with re-opening universities can be mitigated with layered interventions. Nat Commun 12, 5017 (2021). https://doi.org/10.1038/s41467-021-25169-3 